\title{
Cell proliferation after ischemic injury in gerbil brain
}

\section{An immunocytochemical and autoradiographic study}

\author{
M. du Bois, P.D. Bowman, and G.W. Goldstein \\ Departments of Pediatrics and Neurology, University of Michigan, Ann Arbor, Michigan, USA
}

\begin{abstract}
Summary. Tritiated thymidine autoradiography was used to measure cellular proliferation after ischemic injury in gerbil brain. Gerbils were subjected to bilateral occlusion of the common carotid arteries which resulted in areas of necrosis, or infarcts, in the posterior thalamus or midbrain. From $12 \mathrm{~h}$ to 10 days following the ischemia, gerbils were injected with ${ }^{3} \mathrm{H}$ thymidine, sacrificed $4 \mathrm{~h}$ later, and the brains sectioned. In order to identify astrocytes and monocytes/macrophages, immunocytochemistry was performed prior to autoradiography, using antisera against glial fibrillary acidic protein and endothelial-monocyte reticuloendothelial antigen, respectively. Immunocytochemistry was also used to visualize microvessel laminin, myelin, and leakage of serum albumin. Lastly, a histochemical procedure for acid phosphatase activity was employed to verify cellular phagocytic activity in the wound. A reproducible sequence of reactions took place during the first 10 days after ischemia. Early changes included leakage of albumin and myelin breakdown, followed by arrival of monocytes at 2 days and their differentiation into macrophages by 5 days. These cells exhibited intense proliferation from 2 to 6 days post-ischemia. Microvessel endothelial cells were maximally labeled at 4 days post-ischemia. Hypertrophied astrocytes were apparent at 2 days and proliferated from 3 to 7 days post-ischemia, and by 10 days the wound was replaced by a "glial scar".
\end{abstract}

Key words: Brain lesions $-{ }^{3} \mathrm{H}$ Thymidine incorporation - Astrocytes - Monocytes/Macrophages - Capillaries Ischemia - Mongolian gerbil

Although cells of the central nervous system of the adult normally have a very low turnover rate, proliferation of glia and microvessel endothelial cell occurs in response to certain types of injury. That cellular proliferation occurs following ischemic infarction has been suggested from histological examination of human autopsy material and animal models of ischemia, but little quantitative data exists regarding the multiplication of specific cell types in the infarcted area. The paucity of quantitative data has been due in part to a lack of an animal model in which infarction is consistently produced and in which proliferative re-

Send offprint requests to: Monica du Bois, Pediatric Neurology, R6060 Kresge II, University of Michigan, Ann Arbor, Michigan 48109 , USA sponses can be reliably monitored. In a previous report (du Bois et al. 1985) we have shown that large, well-demarcated areas of severe damage, or infarcts, are produced in the posterior thalamus/midbrain region in gerbils by bilateral carotid occlusion and that a reproducible sequence of cellular proliferation occurs as a function of time after the ischemic insult.

In the present study, autoradiography was coupled with immunocytochemistry in order to identify the cell types that proliferate in response to ischemic injury.

\section{Materials and methods}

\section{Tissue preparation}

Cerebral infarcts were produced in adult Mongolian gerbils, Meriones unguiculatus, of both sexes by clamping the common carotid arteries bilaterally for $45 \mathrm{~min}$. The details of the procedure, including incidence of infarction and survival data, have been reported elsewhere (du Bois et al. 1985). For determining labeling indices as a function of time after the ischemic insult, gerbils were injected on the specified day with ${ }^{3} \mathrm{H}$ thymidine $(2 \mu \mathrm{Ci} / \mathrm{g}$ body weight, intraperitoneally). Four hours later, they were perfusion-fixed with $10 \%$ formalin in phosphate-buffered saline or fixed by submersion in absolute ethanol and embedded in paraffin or plastic (JB4 plastic embedding compound, Polysciences, Inc., Warrington, PA). $6 \mu \mathrm{m}$ paraffin or $2 \mu \mathrm{m}$ plastic sections were prepared for immunocytochemistry and autoradiography as noted.

For pre-ischemia labeling experiments, which were designed in order to identify blood-borne macrophages in the infarct, four gerbils were injected every $8 \mathrm{~h}$ for 3 days with ${ }^{3} \mathrm{H}$ thymidine $(3 \mu \mathrm{Ci} / \mathrm{g}$ body weight). This protocol has been reported to result in a high degree of labeling of the monocyte proliferating pool (Volkman and Sawyer 1981). Eight $h$ after the last injection, half of the animals were subjected to $45 \mathrm{~min}$ of ischemia. Five days later, all of the gerbils were perfusion-fixed and the brains embedded in JB4, and autoradiography was performed on sections containing the infarcts.

\section{Histochemistry and immunocytochemistry}

In order to demonstrate acid phosphatase activity in macrophages in the injured brain regions, sections of formalinfixed tissue were incubated overnight in AS-MX phosphate 
Table 1. Sequence of histological reactions in the infarct ${ }^{\mathrm{a}}$

\begin{tabular}{|c|c|c|c|c|c|c|c|c|c|c|c|}
\hline & $12 \mathrm{~h}$ & $1 \mathrm{~d}$ & $2 \mathrm{~d}$ & $3 \mathrm{~d}$ & $4 \mathrm{~d}$ & $5 \mathrm{~d}$ & $6 \mathrm{~d}$ & $7 d$ & $8 \mathrm{~d}$ & $9 \mathrm{~d}$ & $10 \mathrm{~d}$ \\
\hline Degenerating neurons and glia ${ }^{b}$ & + & ++ & +++ & $++t$ & ++ & $+t$ & + & + & + & + & 0 \\
\hline Myelin degradation $^{c}$ & $+/ 0$ & + & + & + & + & + & ++ & ++ & ++ & ++ & +++ \\
\hline Monocytes/macrophages ${ }^{d}$ & 0 & 0 & + & ++ & $+t$ & ++ & +++ & +++ & ++ & + & + \\
\hline Reactive astrocytes ${ }^{e}$ & 0 & 0 & + & + & + & ++ & ++ & ++ & +++ & $++t$ & $++t$ \\
\hline Hypertrophied capillaries ${ }^{f}$ & 0 & 0 & 0 & 0 & $+/ 0$ & + & + & ++ & ++ & ++ & ++ \\
\hline Acid phosphatase activity ${ }^{g}$ & 0 & 0 & 0 & 0 & 0 & ++ & +++ & +++ & ++ & +10 & 0 \\
\hline
\end{tabular}

a The various reactions were determined by microscopically comparing sections of infarcts from brains at different times after ischemia.

0 , no detectable difference from control; + , slight reaction; $+/ 0$, slight reaction in some animals but not detectable in others;

++ , moderate reaction; +++ , intense reaction

b Evaluated by observation of pyknotic nuclei in hematoxylin-stained tissue

c Evaluated as loss of anti-myelin basic protein immunostaining

d Presence monitored in plastic or immunostained paraffin sections

${ }^{e, f}$ Evaluated in immunostained sections, utilizing anti-GFAP and anti-laminin, respectively

8 Visualized histochemically

acid and fast blue RR salt (Sigma), as described by Kaplow and Burstow (1964). The sections were rinsed thoroughly in distilled water, air dried, and mounted with Permount.

For immunocytochemical localization of glial fibrillary acidic protein (GFAP), myelin basic protein, albumin, and laminin, paraffin sections of formalin- or ethanol-fixed brains were mounted onto Histostik-coated (Accurate Chemical and Scientific Corp., Westbury, N.Y.) coverslips and allowed to dry overnight on a warm plate. Demonstration of laminin in formalin-fixed tissue required pretreatment with $0.2 \%$ pepsin in $0.01 \mathrm{~N} \mathrm{HCl}$ for $20 \mathrm{~min}$ at $37^{\circ} \mathrm{C}$. Staining was accomplished by the avidin/biotin peroxidase method (Vector Laboratories, Burlingame, CA.) directed against the appropriate first antibody. Rabbit anti-human GFAP was a gift from Dr. L. Eng, Stanford University, and used at a dilution of $1: 1000$. Rabbit anti-mouse laminin (Bethesda Research Labs, Gaithersburg, MD) was used at 1:500. Rabbit anti-rat albumin (Cappel Laboratories, Cochranville, PA) was used at 1:2000. A monoclonal antibody to myelin basic protein (Hybritech, Inc. San Diego, CA) was used at 1:20000. Lastly, IgG isolated from chicken egg yolk that reacted specifically with rodent monocytes, macrophages, and endothelial cells was used to identify monocytes and macrophages. This antibody most likely is directed against the reticuloendothelial E-M antigen system (Moraes and Stastny 1977), as absorption with peritoneal macrophages or endothelial cells removed its ability to stain sections. Following the staining procedure, the sections were dehydrated and mounted with Permount or, for autoradiography, air dried and mounted section-side-up onto microscope slides with a small amount of vacuum grease.

\section{Autoradiography}

Microscope slides bearing the sections were dipped in Kodak NTB2 emulsion, stored at $4^{\circ} \mathrm{C}$ for 12-20 days then developed in cold $\left(10^{\circ} \mathrm{C}\right)$ Kodak D19 developer and fixed. Paraffin sections previously stained immunocytochemically were counterstained with hematoxylin and the coverslips were removed from the slides, air dried, and mounted section-side-down with Permount. Vacuum grease was removed by swabbing with absolute ethanol. JB4 sections were stained with azure II/methylene blue, air dried, and mounted with Permount. Autoradiographs of sections through the approximate center of each infarct were used for quantitation of ${ }^{3} \mathrm{H}$ thymidine labeled cells. Per cent labeled astrocytes was calculated by counting all labeled and unlabeled GFAP-positive cells in the infarcted area. Similarly, all labeled and unlabeled E-M antigen positive cells were counted to determine the per cent labeled monocytes/macrophages. Capillary proliferation was determined in conventionally stained paraffin or plastic sections by counting all labeled and unlabeled microvessel endothelial cells across the diameter of the infarct. At least 500 of each of the three cell types were counted per infarct.

\section{Results}

Areas of severe brain damage (infarcts) from 35 gerbils were examined from $12 \mathrm{~h}$ to 10 days following the ischemic insult. Immunocytochemical and histochemical methods were used qualitatively to monitor vascular leakage, myelin degradation, phagocytic activity, and hypertrophy of astrocytes

Fig. 1. a Low magnification immunocytochemical demonstration of albumin leakage in thalamic infarct, 1 day after ischemia, visualized by brown DAB reaction product. Microvessels in normal brain are impermeable to albumin. $\times 50$. b Higher magnification of vessels in a. Note concentration of reaction product in pericytes (arrowheads) as well as the neuropil. $\times 300$. c Low magnification micrograph demonstrating GFAP-immunostained cells forming a ring around the core of the infaret. Six days post-ischemia. $\times 50$. d Autoradiograph of GFAP-immunostained section, 3 days post-ischemia, showing three astrocytes with ${ }^{3} \mathrm{H}$ thymidine-labeled nuclei $(\mathrm{arrowheads})$. $\times 1250$. e Low magnification view of section adjacent to one shown in c, demonstrating a positive histochemical reactions for acid phosphatase activity at six days post-ischemia in the center of the infarct. $\times 50$. f Autoradiograph of an E-M antigen immunostained section, 3 days post-ischemia. In the field are $2 \mathrm{E}-\mathrm{M}$ positive cells that are also ${ }^{3} \mathrm{H}$ thymidine labeled. Labeled cell in lower right field is probably an astrocyte. $\times 1250$. g Low magnification micrograph of infarct after immunostaining with antibody against myelin basic protein, 10 days post-ischemia. There has been marked degeneration of myelin in the infarct. $\times 50$. h Low magnification micrograph of blood vessels in the infarct, demarcated by arrowheads, and adjacent normal tissue as visualized by anti-laminin immunocytochemistry, 7 days post-ischemia. The microvessels in the infarct stain more intensely and appear to be at a higher density in the infarct as compared to the adjacent, normal tissue. $\times 50$ 

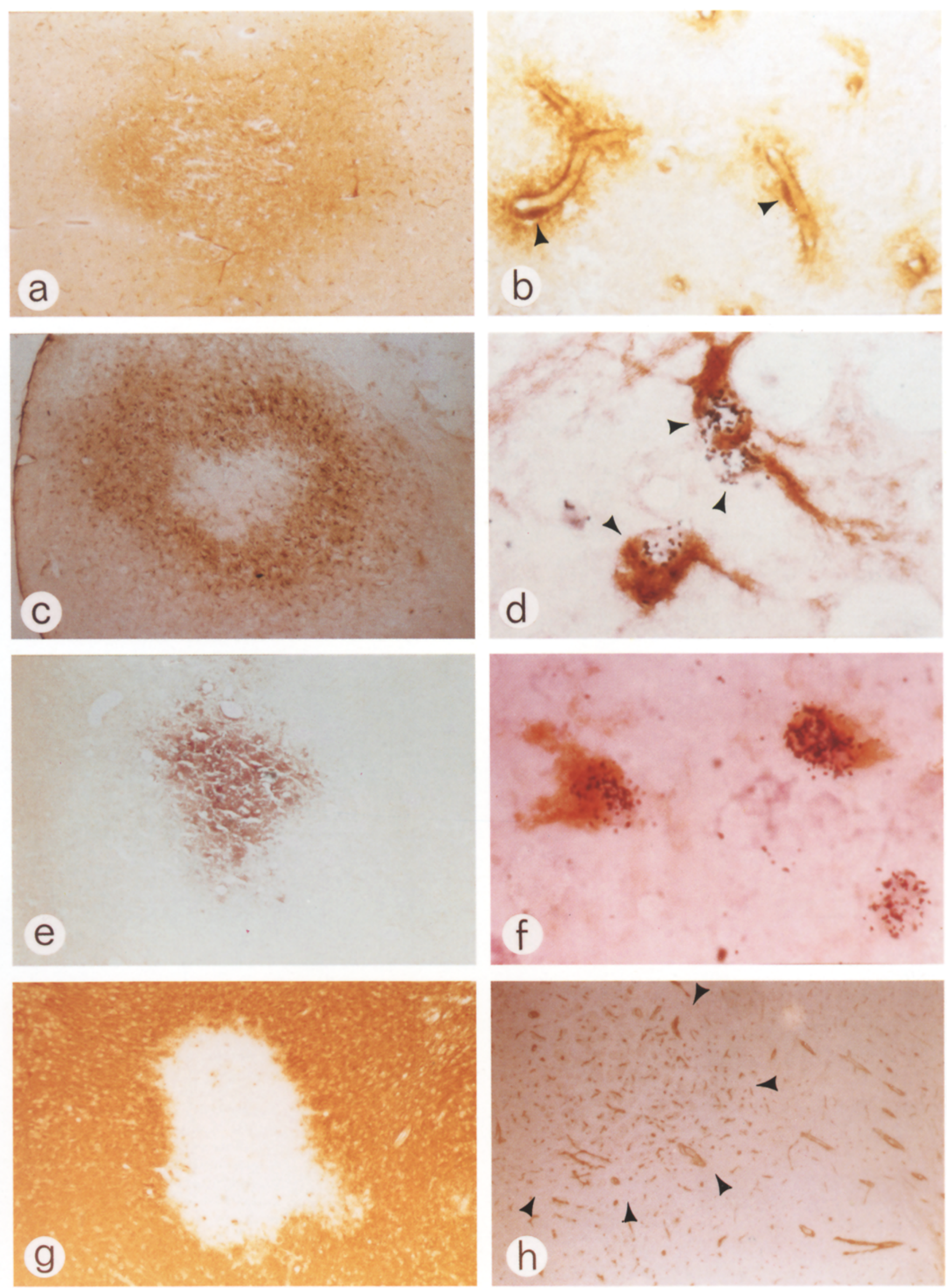


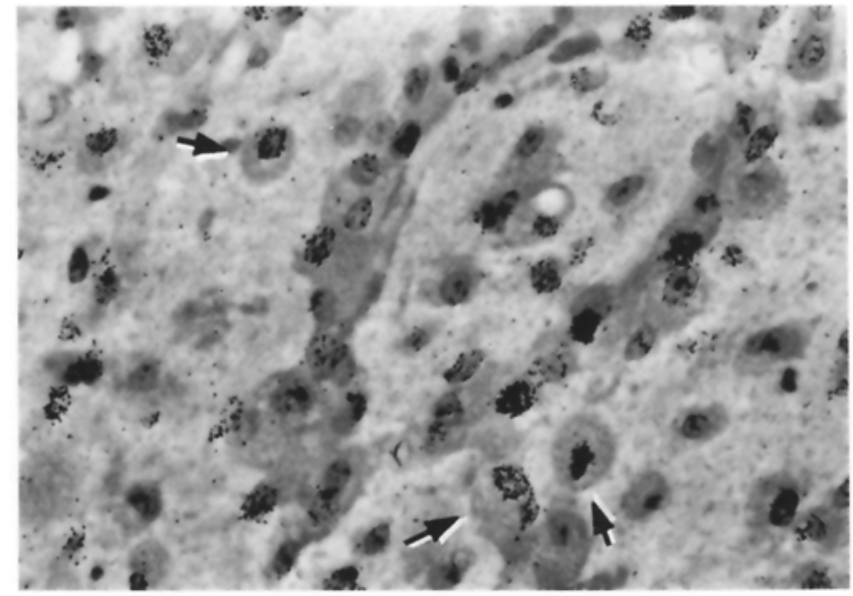

Fig. 2. Autoradiograph through 5 day infarct from animal that was labeled with ${ }^{3} \mathrm{H}$ thymidine prior to ischemia. The majority of cells in the field are macrophages (arrows on a few of them) and most are labeled. Methylene blue/Azure II; $\times 500$

and microvessels. Proliferation of cells was quantified by pulse-labeling the animals with ${ }^{3} \mathrm{H}$ thymidine, which labels radioactively all cells that are at that time in the DNA synthetic phase of the cell cycle, and autoradiography. The sequence of cell and tissue reactions in the infarct is summarized in Table 1.

The infarcts, which measured roughly $0.8-1 \mathrm{~mm}$ in diameter in coronal sections, were consistently located in caudal thalamus or rostral midbrain. Leakage of serum components through vessel walls and into the neuropil was apparent $12 \mathrm{~h}$ following ischemia (Fig. $1 \mathrm{a}$ ). Some albumin appeared to become concentrated in pericytes (Fig. $1 \mathrm{~b}$ ). No extravasation of erythrocytes was observed. Myelin degeneration was apparent at 1 day and became more pronounced with time (Fig. $1 \mathrm{~g}$ ).

Beginning at 2 days, enlarged astrocytes which stained intensely with antisera against GFAP, "reactive astrocytes," were present in a concentric zone surrounding a central core of degenerating neurons (Fig. 1c). In control brains, GFAP-positive processes were not detected, and individual astrocytes were difficult to see. This zone of reac- tive astrocytes increased in density during the next several days, and this appeared to occur as a consequence of cell proliferation, as demonstrated by nuclear ${ }^{3} \mathrm{H}$ thymidine incorporation (Fig. 1d). Maximum labeling was observed at 3-6 days post-ischemia. At approximately 1 week, thick GFAP-positive fibers were oriented from the cell bodies toward the center of the infarct, and by 10 days these had penetrated almost to the center of the infarct forming a "glial scar."

Leukocytes were scarce in the $12 \mathrm{~h}$ and 1 day infarcts. At 2 days, however, numerous cells which reacted positively with antisera to the E-M antigen were located in the damaged area. A high percentage of these cells were labeled (Fig. 1f). Some of these cells were monocytes, others resembled microglia, with long, thin nuclei and delicate, bipolar processes, while many others had irregular amoeboid shapes. By 3 days, these cells were more numerous, and at 4 days they began to assume characteristics of active phagocytes, such as abundant cytoplasm with lipid inclusions and lysosomes with acid phosphatase activity (Fig. 1e). Immunostained sections demonstrated the presence of myelin basic protein in the inclusions. These cells also exhibited intense proliferative activity. Numerous macrophages were still present at 10 days, most of them clustered about the vessels, although they no longer demonstrated detectable acid phosphatase activity or ${ }^{3} \mathrm{H}$ thymidine labeling.

In order to obtain information about the source of the macrophages, gerbils were labeled continuously for 3 days with ${ }^{3} \mathrm{H}$ thymidine prior to, and sacrificed 5 days after, ischemia, and analyzed autoradiographically (Fig. 2). In this experiment, the isotope was used not to obtain an estimate of cell proliferative activity, but rather as a means of "tagging" cells of hematogenous origin (Volkman and Sawyer 1981). $91 \%$ of the macrophages in the infarct were labeled. Labeled astrocytes were not observed, indicating that the isotope was not reutilized to a significant extent following ischemia. In control gerbils which underwent the same protocol except for the ischemic insult, only $1.8 \%$ of the total cell population in the corresponding midbrain area was labeled. These results indicate that the majority of macrophages found in the infarct were derived from circulating rather than resident cells.

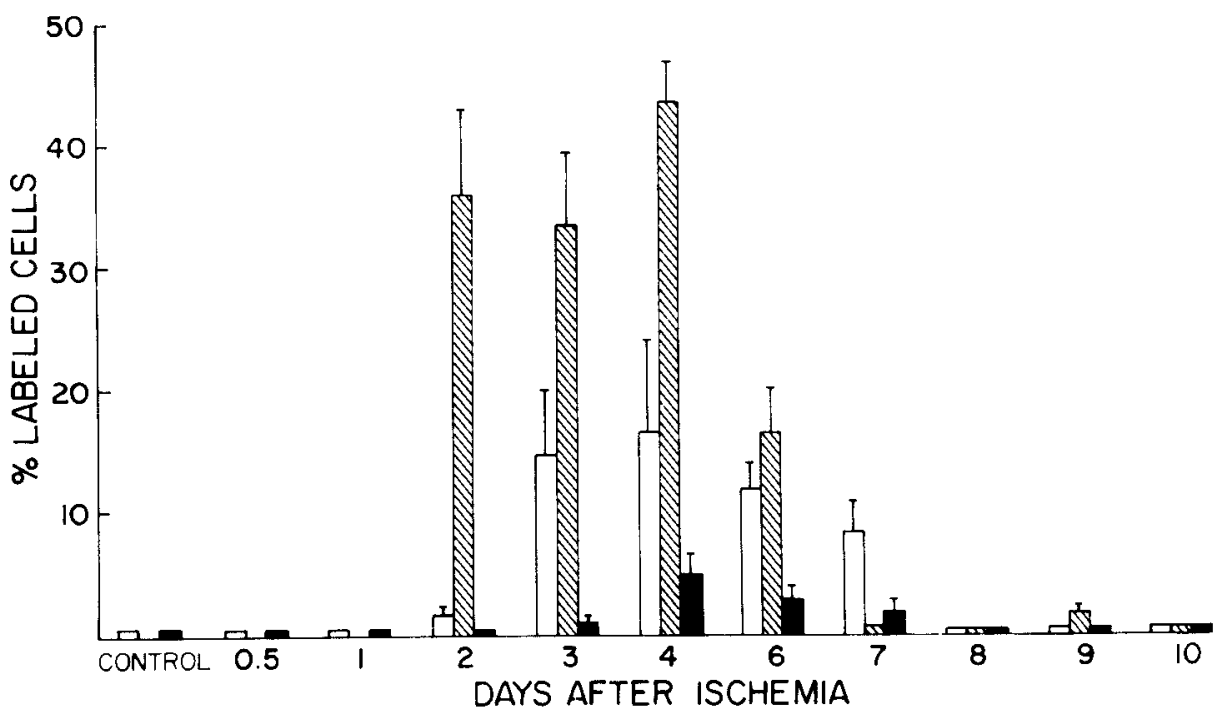

Fig. 3. Time course of ${ }^{3} \mathrm{H}$ thymidine incorporation in astrocytes, monocytes/ macrophages, and endothelial cells after infarction. Open bars, GFAPpositive cells; hatched bars, E-M antigen positive cells; solid bars, microvessel endothelial cells. Monocytes/macrophages were not present in control brains or before 2 days post-ischemia. Data represent the mean of 2 , or the mean $+\mathrm{SD}$ of 3 , infarcts per time point 
Blood vessels were examined in conventionally stained paraffin and plastic sections and in immunostained sections using antisera against the basement membrane component laminin. Capillaries in the damaged area appeared morphologically normal, with no evidence of extravasated red blood cells, until 4-5 days post-ischemia, after which time they stained more intensely than those in the surrounding tissue. By 7 days the density of microvessels was clearly greater in the infarct than in surrounding tissue (Fig. $1 \mathrm{~h}$ ).

Tritiated thymidine incorporation in astrocytes, monocyte/macrophages, and microvessel endothelial cells in the infarcted areas as a function of time after the ischemic insult is illustrated in Fig. 3. No incorporation above control was observed at $12 \mathrm{~h}$ or 1 day. At 2-4 days, however, accumulating monocytes and macrophages exhibited very intense proliferative activity which declined by 7 days. Appreciable labeling of reactive astrocytes was first seen at 3 days and continued at this high level for 3 more days. Microvessel endothelial cells were maximally labeled at 4 days. The proliferative activity of these cells was not as marked as the other cell types.

\section{Discussion}

Although several histological studies have been made of experimental ischemic infarction (DeGirolami et al. 1984; Garcia and Kamijyo 1974; Ito et al. 1975), relatively little is known about the proliferative responses of specific cell types in the brain after ischemic injury. In the present study, utilizing immunocytochemistry coupled with autoradiography, we have determined the time course of ${ }^{3} \mathrm{H}$ thymidine incorporation in the principal cell types responding to severe ischemia in gerbil brain. To our knowledge, this is the first reported study to utilize this technique after ischemia. It is generally accepted that cells which incorporate ${ }^{3} \mathrm{H}$ thymidine into nuclear DNA proceed through the cell cycle to divide and that tritiated thymidine autoradiography is a reliable tool for studying cell proliferation (Cameron 1971). In this model, a burst of DNA synthetic activity took place at 2-7 days after the ischemic insult. Monocytes and macrophages, which were shown to be principally blood-derived, exhibited the most intense activity, followed by astrocytes and microvessel endothelial cells. In addition to measuring cell proliferation, histochemical and immunocytochemical methods were used qualitatively to monitor albumin leakage, myelin degradation and cellular phagocytic activity in order to visualize better the processes of injury and repair in this model.

Oligodendrocytes were not examined in great detail following the ischemic episode. They appeared to degenerate rapidly, and ${ }^{3} \mathrm{H}$ thymidine-labeled, myelin basic proteinpositive cells were not observed in the area of the infarct after ischemia. Similarly, ${ }^{3} \mathrm{H}$ thymidine-labeled oligodendrocytes were not detected in kainic acid-induced lesions (Murabe et al. 1981). Oligodendrocytes have been reported to be the second most vulnerable brain cell type to injury after neurons (Dudley 1982). There is some evidence that this cell type is capable of reproducing following injury (Bologa et al. 1984; Ludwin 1984), but the proliferative activity may occur some distance from the necrotic area (Persson 1976).

The lesion produced in the present ischemia model appears similar to stab, and other severe, wounds to the brain with respect to damage and repair processes. Astrocytes are known to hypertrophy and multiply following a wide variety of brain lesions, including mechanical wounds (Persson 1976; Latov et al. 1979; Cavanagh 1970; Azmitia and Whitaker 1983), kainic acid-induced lesions (Murabe et al. 1981, 1982), and ischemia (Ito et al. 1975; Petito and Babiak 1982; Slager 1970). Macrophages, too, are ubiquitous in brain lesions, and several investigators have provided evidence that these are derived predominantly from circulating monocytes (Fujita et al. 1981; Persson et al. 1978; Oehmichen 1978; Tsuchihashi et al. 1981). The sequence of post-infarction reactions described here appears to mimic closely that which has been reported to occur in the human brain following stroke.

While activated macrophages could be identified readily with conventional stains by virtue of the foamy appearance of the cytoplasm, and phagocytic activity confirmed by demonstrating intracellular acid phosphatase activity, accurate identification of intermediate forms between monocytes and full-blown macrophages that were present in the damaged area during the first 4 days post-ischemia was difficult. To identify these cells, therefore, antibody against E-M antigens was utilized. Positive immunostaining was detected on monocytes, amoeboid cells, and macrophages. Labeling indices of macrophages immunostained by this antibody were virtually identical to those of adjacent sections visualized by conventional histological stains such as luxol fast blue/P.A.S./hematoxylin. Immunostained microglia were not observed in control brain with this antibody, although cells which had the morphology of microglia, i.e., slender nucleus and short bipolar processes, and which bound the antibody were observed in the infarcts early after ischemia. Although the pre-labeling experiments indicated that resident microglia did not constitute a significant percentage of the phagocytic cells in the infarct, the possibility cannot be ruled out that resident microglia are activated by ischemia to acquire the E-M antigen. Similar results have been noted by Murabe and Sano (1983), Tsuchihashi et al. (1981), and Wood et al. (1979) who found that antimacrophage antisera bound microglia-like cells in injured, but not normal adult brain. Indeed, there has been considerable controversy over the origin of the microglial cell and its relatedness to the blood monocyte. There is also some evidence that pericytes and "perithelial" cells in the brain can become macrophages (Boya 1976; Mato and Mato 1983). While these cells might participate in removing debris, data from the present study suggests that they probably do not migrate from their vessel-associated position to join the pool of macrophages in the necrotic area.

The nature of the increased intensity of laminin immunostaining of microvessels in the infarcted area is uncertain at this time. Garcia and Kamijyo (1974) have reported capillary basement membrane thickening following ischemia in a primate model, and preliminary electron microscopic investigation of 8-day infarcts suggests that this also occurs in the present gerbil model (data not shown). However, additional factors, such as differences in tissue consistency between the infarct and surrounding neuropil, or unmasking of laminin antigenicity by macrophage proteolytic enzymes, might be contributory to the observed staining discrepancy. Further studies are also needed to determine the severity of damage imparted by the ischemic insult to the endothelial cells. Although the blood-brain barrier was disrupted early after ischemia, as shown by albumin immunocytochemistry, the mechanism for this could not be determined at the light-microscopic level. Electron-microscopic 
examination of 3-day infarcts revealed that the endothelial cells appeared normal despite surrounding damaged tissue (unpublished results). The reason for the observed increase in microvessel density is not completely clear. While endothelial labeling which might have resulted in the formation of new capillaries did occur during the week following the ischemia, no sprouting capillaries were observed during the time studied. It is also likely that contraction of the damaged area occurred, thereby artifactually increasing the capillary density. The labeled capillary endothelial cells might represent replacement of damaged endothelial cells or a hypertrophic response caused by the ischemia.

The stimuli which lead a particular cell, such as an astrocyte or endothelial cell, to leave its normally quiescent state and divide are largely unknown. Several substances, however, have been identified recently which may have a role in post-infarction cell proliferation. Platelet-derived growth factor from serum has been shown to be a potent mitogen for glia, fibroblasts, and smooth muscle cells (Heldin et al. 1981; Ross et al. 1974) and may diffuse into an infarcted area following disruption of the blood-brain barrier. Also, Brockes et al. (1980) have described a substance from pituitary and brain that stimulates astrocyte and Schwann cell mitosis. A macrophage-derived factor which stimulates endothelial cell proliferation has been isolated (Gimbrone et al. 1982; Ziats and Robertson 1981), and this factor may become available upon arrival of monocytes and their conversion into phagocytic macrophages. Finally, neural tissue itself is a source of a variety of substances which have been shown to stimulate cell multiplication, including fibroblast growth factor (Gospodarowicz 1975), endothelial cell growth factor (Maciag et al. 1982), and brain-derived growth factor (Barritault et al. 1982). Possibly, such substances are released into the neuropil from ischemic, degenerating neurons and stimulate proliferation of non-neuronal cells.

The relative ease with which reproducible infarcts can be produced in the gerbil brain by carotid ligation has established this animal as a model for studying brain ischemia. In the present study, utilizing ${ }^{3} \mathrm{H}$ thymidine incorporation to monitor cellular proliferation, we have demonstrated that astrocytes, macrophages, and to some extent endothelial cells actively multiply in the injured area, resulting in the removal of necrotic debris and the production of a glial scar. Since a similar sequence of events appears to occur in human infarcts, this model should be useful for understanding and ultimately manipulating the processes of damage and repair in human brain.

\section{References}

Azmitia EC, Whitaker PM (1983) Formation of a glial scar following microinjection of fetal neurons into the hippocampus or midbrain of the adult rat: An immunocytochemical study. Neurosci Lett 38:145-150

Barritault D, Plouët J, Courty J, Courtois Y (1982) Purification, characterization, and biological properties of the eye-derived growth factor from retina: Analogies with brain-derived growth factor. J Neurosci Res 8:477-490

Bologa L, Z'graggen A, Herschkowitz N (1984) Proliferation rate of oligodendrocytes in culture can be influenced by extrinsic factors. Dev Neurosci 6:26-31

Boya J (1976) An ultrastructural study of the relationship betwen pericytes and cerebral macrophages. Acta Anat (Basel) 95: 598-608
Brockes JP, Lemke GE, Balzer DR (1980) Purification and preliminary characterization of a glial growth factor from bovine pituitary. J Biol Chem 225:8374-8377

Cameron IL (1971) Cell proliferation and renewal in the mammalian body. In: Cameron IL, Thrasher JD (eds) Cell and molecular renewal in the mammalian body. Academic Press, New York, pp 45-85

Cavanagh JH (1970) The proliferation of astrocytes around a needle wound in the rat brain. J Anat 106:471-487

DeGirolami U, Crowell RM, Marcoux FW (1984) Selective necrosis and total necrosis in focal cerebral ischemia. Neuropathologic observations on experimental middle cerebral artery occlusion in the macaque monkey. $J$ Neuropathol Exp Neurol 43:57-71

du Bois M, Bowman PD, Goldstein GW (1985) Cell proliferation after ischemic infarction in gerbil brain. Brain Res (in press)

Dudley A (1982) Cerebrospinal blood vessels normal and diseased. In: Haymaker W, Adams RD (eds) Histology and histopathology of the nervous system Vol. 1, Charles C Thomas, Springfield, Illinois, pp 714-797

Fujita S, Tsuchihashi Y, Kitamura T (1981) Origin, morphology and function of microglia. In: Glial and neuronal cell biology, Eleventh Internat Congr Anat, Alan R. Liss, Inc, New York, pp 141-169

Garcia JH, Kamijyo Y (1974) Cerebral infarction. Evolution of histopathological changes after occlusion of a middle cerebral artery in primates. J Neuropathol Exp Neurol 33:408-421

Gimbrone MA, Martin BM, Baldwin WM, Unanue ER, Cotran RM (1982) Stimulation of vascular cell growth by macrophage products. In: Nossel HL, Vogel HJ (eds) Pathobiology of the endothelial cell, Academic Press, New York, pp 3-16

Gospodarowicz D (1975) Purification of a fibroblast growth factor from bovine pituitary. J Biol Chem 250:2515-2520

Heldin CH, Westermark B, Wasteson A (1981) Specific receptors for platelet-derived growth factor on cells derived from connective tissue and glia. Proc Natl. Acad Sci USA 78:3664-3668

Ito U, Spatz M, Walker JT, Klatzo I (1975) Experimental cerebral ischemia in mongolian gerbils. I. Light microscopic observations. Acta Neuropathol (Berl) 32:209-223

Kaplow L, Burstow M (1964) Cytochemical demonstration of acid phosphatase in hematopoietic cells in health and in various hematological disorders using azo dye technique. J Histochem Cytochem 12:805-811

Latov N, Nilaver G, Zimmerman EA, Johnson WG, Silverman A, Defendini R, Cote L (1979) Fibrillary astrocytes proliferate in response to brain injury. A study ombining immunoperoxidase technique for glial fibrillary acidic protein and radioautography of tritiated thymidine. Dev Biol 72:381-384

Ludwin SK (1984) Proliferation of mature oligodendrocytes after trauma to the central nervous system. Nature 308:274-275

Maciag T, Hoover GA, Weinstein R (1982) High and low molecular weight forms of endothelial cell growth factor. J Biol Chem 257:5333-5336

Mato M, Mato TK (1983) Distribution and number of fluorescent granular perithelial cells in coronal sections of rats cerebrum. Experientia 39:1374-1376

Moraes JR, Stastny P (1977) A new antigen system expressed in human endothelial cells. J Clin Invest 60:449-454

Murabe Y, Sano Y (1983) Morphological studies on neuroglia. VII. Distribution of "brain macrophages" in brains of neonatal and adult rats, as determined by means of immunohistochemistry. Cell Tissue Res 229:85-95

Murabe Y, Ibata Y, Sano Y (1981) Morphological studies on neuroglia II. Response of glial cells to kainic acid-induced lesions. Cell Tissue Res 216:569-580

Murabe Y, Ibata Y, Sano Y (1982) Morphological studies on neuroglia. IV. Proliferative response of non-neuronal elements in the hippocampus of the rat to kainic acid-induced lesions. Cell Tissue Res 222:223-226

Oehmichen M (1978) Mononuclear phagocytes in the central nervous system. Springer, Berlin 
Persson L (1976) Cellular reactions to small cerebral stab wounds in the rat frontal lobe. An ultrastructural study. Virchows Arch [Cell Pathol] 22:21-37

Persson LI, Ronnback L, Losengren LE (1978) Identification of reactive cells in injured brain. Acta Neurol Scand (Suppl) 67:245-246

Petito CK, Babiak T (1982) Early proliferative changes in astrocytes in postischemic noninfarcted rat brain. Ann Neurol 11:510-518

Ross R, Glomset J, Kariya B, Harker L (1974) A platelet-dependent serum factor that stimulates the proliferation of arterial smooth muscle cells in vitro. Proc Natl Acad Sci USA $71: 1207-1210$

Slager UT, Basic neuropathology, Williams \& Wilkins Co., Baltimore (1970) pp 50
Tsuchihashi Y, Kitamura T, Fujita S (1981) Immunofluorescence studies of the monocytes in the injured rat brain. Acta Neuropathol (Berl) 53:213-219

Volkman A, Sawyer R (1981) Systemic labeling of mononuclear phagocytes. In: Adams D, Edelson P, Koren H (eds) Methods for studying mononuclear phagocytes. Academic Press, New York, pp 996-981

Wood GW, Gollahan KA, Tilzer SA, Wars T, Morantz RA (1979) The failure of microglia in normal brain to exhibit mononuclear phagocyte markers. J Neuropathol Exp Neurol 38:369-376

Ziats NP, Robertson AC (1981) Effects of peripheral blood monocytes on human vascular cell proliferation. Atherosclerosis $38: 401-410$

Accepted April 29, 1985 